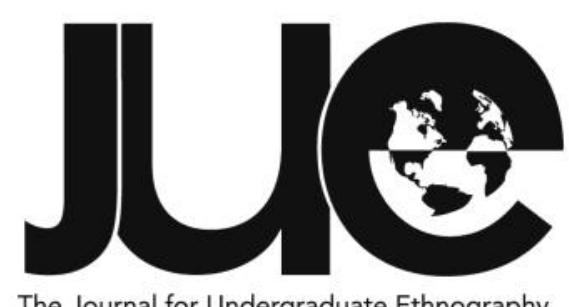

The Journal for Undergraduate Ethnography

\title{
Sameness and Difference: Asserting Cultural Identity Through Multicultural Experience and Negotiation
}

\section{Sarah I. Han}

Wheaton College, sarahirenehan@gmail.com

\section{ABSTRACT}

Multiculturalism "seeks to use cultural diversity as a basis for challenging, revising, and relativizing basic notions and principles common to dominant and minority cultures alike" (Turner 1993, 413). This paper explores the assertion of ethnic minority Baloch women's cultural identity through the lenses of marriage, nationalism, and education. Drawing on linguistic analysis, it shows that Baloch women in Al Ain construct their multicultural identity by navigating between the structures of tradition and personal agency: they replace kin endogamy with marriage with those who are culturally similar; develop a sense of nationalism that negotiates between their country of origin and their country of adoption, regardless of their citizenship; and pursue complex paths involving education and marriage among the opportunities presented by family and state support. The displaced Baloch community in the United Arab Emirates, underrepresented in academic research, contributes uniquely to conversations of multiculturalism, ethnic minorities, nationalism, and gender in the Middle East, a non-white, Muslim-majority context, with implications for global mass movements of refugees, women's rights, and ethnic and racial minorities.

Keywords: multiculturalism, displacement, nationalism, kinship, Middle East, gender 


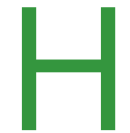

ello?" My voice is met by the sound of dogs barking and I turn back to my mother's friend and assure her, "This is the right home." Seeing Ameera wave in welcome from the doorway of the house, I step over the threshold of the iron gate, faded pale blue from the desert sun. My mother's friend follows closely behind. As a single, Asian American woman, I enter into the lives of participants as a visible outsider. I visit these women with my mother or a friend of my mother, rather than travelling alone. The presence of an older, married woman chaperoning my actions in public signals sensitivity to the tangible cultural expression of protection and decency for a young, unmarried woman.

We enter the majlis [sitting room] where Umm Rashid stands up to greet us. Four kisses on one cheek and the greeting "Kif halich? [How are you?]" The whirring of a fan fights against the summer heat and almost overwhelms the low hum of the Pakistani game show on the TV. As she sits down and throws her scarf over her shoulder, the iconic Balochi pocket, heavy with embroidery, drapes gently on the ground. This characteristically Balochi outfit has been referenced by many of the younger participants as the outfit their mothers always wear, but they only don for weddings or eids [festivals]. Settling into the cushion on the floor, I hear Asma's words echo in my ear, "We all originally are Baloch. So we have the same things in common...'cause we all have the same culture, the same food habit, the same dressing style, everything is same."

The Baloch people have a long history in the United Arab Emirates (UAE). Originating in Balochistan, a province spanning the western side of Pakistan, eastern Iran, and southern Afghanistan, today the Baloch people live in countries all over the world with many residing in the Middle East. Many people, including the Baloch, moved to the UAE for economic opportunity as the country discovered oil and began to build up industries under the vision and leadership of Sheikh Zayed bin Sultan Al Nahyan (Davidson 2006). Because of political ties between colonized areas in and around Balochistan and the British presence in what is now known as the UAE, as well as the religious affinity felt between Sunni Arabs and Sunni Persians, Baloch immigrants could move across borders to the Emirates without passports before the Emirates became independent in 1971 (Zayed University n.d., Abdullah 1978). As documentation became more important, the UAE government offered many Baloch people the choice of local citizenship or citizenship from their countries of origin, Pakistan and Iran. More recently, the Emirati government has given local citizenship or Comoros Island passports to many of those who were formerly known as bidoon [outside], lacking passports, and thus lacking the documents necessary to enroll children in school, access healthcare, obtain a work permit, open a bank account, and travel easily within the U.A.E. and across national borders (Arbrahamian 2015; Zacharias 2013; Bureau of Democracy, Human Rights and Labor 2008). Because of the large expatriate population in the UAE, the Emirates is a country of minorities, with local Emiratis making up only 15 percent of the total population (Central Intelligence Agency n.d.). A study of the Baloch, as a diaspora people, provides a means to examine themes that are pertinent in a transnational world, including multicultural identity construction, assimilation and distinctiveness (Ali 2011). The more specific exploration of identity construction in Baloch women has implications for gender studies of other diaspora communities, especially as they intersect with familial, ethnic, and national identity.

Multiculturalism "seeks to use cultural diversity as a basis for challenging, revising, and relativizing basic notions and principles common to dominant and minority cultures alike" (Turner 1993, 413). Multiculturalism can be understood as "numerous cultural identities 
manifested in people and societies" (Rodriguez $2000,153)$. The plurality of cultural identities can be founded in an array of factors including ethnic background, national affiliation, and family history. Navigating multicultural identity involves negotiating values and principles that may be expressed in conflicting or contrasting ways. The conversation around multiculturalism has the valuable potential to challenge and reshape the assumptions of majority and minority cultures. While conversations on multiculturalism have historically been based in Eurocentric assumptions, exploration of multicultural identities in nonwhite majority contexts is critical to deconstruct the othering of non-European derived elements (Eller 1997). Balochi women in Al Ain construct their multicultural identity by navigating between the structures of tradition and personal agency: they replace kin endogamy with marriage with those who are culturally similar; develop a sense of nationalism that negotiates between their country of origin and their country of adoption, regardless of their citizenship; and pursue complex paths involving education and marriage among the opportunities presented by family and state support.

\section{Methods: Narrative Study of Identity Construction}

The initial foundational question of this project was: How do Baloch women in Al Ain construct identity for themselves and their children through education and the retelling of history? As I entered the research process, however, I found that because of the variety of marital statuses as well as generational differences, personal identity was more central than maternal identity in the narratives of these women. While there were distinctions drawn between displaced Baloch and those resident in Balochistan, political and Balochi history were not prominent themes in these women's narratives, especially in conversations with women in their forties and younger. "History", qualified in this context as the retelling of personal or recent family history, can be a useful way of framing the personal narratives of participants. While religion was an important theme within the narratives of individuals, due to the constraints of this paper, it will not be addressed, except as it intersects with the themes explored here. The driving question for this research project was shaped through the process of research and writing and can be stated: How do Baloch women in Al Ain construct their identity through marriage, national affiliation, and education?

To narrow my scope, I limited participants to women over the age of 18, in the city of Al Ain in the UAE. During my research time, I was also introduced to a Baloch woman who lived and worked in Dubai. Since the scope of research was limited to Al Ain, the data from her interview is treated as supplementary rather than the primary focus of analysis. Over the course of this project, I spoke with ten Baloch women. At the time of research, two were single, one engaged, and seven married; one has previously been divorced. Some are mothers of young children and some have children fully grown. In a family-based cultural context, these categorizations significantly shape the expectations, responsibilities, and voices of authority, particularly the role and influence of patriarchs, in these women's lives. Participants held passports from Pakistan, Iran, and the UAE. Citizenship is a major theme in this exploration of identity as it intersects with the family history in the $U A E$, relationship to the local government, educational opportunities, language, and many other important themes. In terms of education, some women had never attended school while others had finished a Bachelors degree and had hopes of eventually completing a doctorate. The educational opportunity for women closely reflects the values of their closest male authority, usually a father or husband. The women ranged in age from their early twenties to late sixties and seventies. Most of the women's families have been in the UAE for several decades, though they maintained different levels of connectivity with relatives and friends in the Balochistan region. The diversity of women in regard to these different factors provides this study with a wide array of perspectives, avoiding a monolithic representation of the experiences of Baloch women.

The basis of this research project is primarily unstructured personal interviews, conducted over the course of three months in public places and homes, according to the preference 
of the participant. Because of the communal nature of the home, interviews conducted in the majlis [sitting room] of the home were not expected to be private. For the sake of clarity, pseudonyms were added in the case of multiple participants with the same name.

One limitation of this research was language. While I, as the researcher, had basic conversational Modern Standard Arabic (MSA) and participants could understand the general ideas I was communicating, the participants spoke a mixture of Khaleeji Arabic, Balochi, Urdu, Farsi, and varying levels of English. The diverse linguistic demographics created challenges in communication and translation. For example, during one visit, I asked questions in Arabic to the mother of the family, Umm Rashid, while her daughter Noora, sitting next to her, translated into Balochi. Umm Rashid responded to my questions in a mixture of Urdu and Balochi and my mother's friend, who is also her long-time family friend, translated back to English for me, mirroring the imagery and spiritual references Umm Rashid used. At one point in the conversation, a dispute between Umm Rashid and some of her daughters over whether the role of women has changed was not fully translated because of limitations in my translator's vocabulary. These recordings were not fully transcribed because participants' original responses were sometimes inaudible due to multiple conversations simultaneously occurring in the majlis [sitting room], which is the hub of family life, and the limitations of this project in finding translators fluent in English, Urdu, Balochi, Khaleeji Arabic and MSA. This situation illustrates the difficulties of research involving several languages and the necessity of translation embedded in the design of this project.

In addition to translation between languages, eight of the interviews were conducted primarily in English. Educated women could converse with a mix of formal MSA and English, depending on their schooling and exposure to native English speakers. When conversing with individuals who knew very little English, the process of communication was more complex. While their meaning was communicated to me through further explanation, movement, and clarification, this indirect method of communication made it difficult to transcribe with precision their exact wording. Interviews were recorded with the permission of the participant. In four cases where participants requested that I not use a recording device, I took notes on their responses. Quotations from these unrecorded interviews are approximate rather than precise, written to capture the participant's cadence of speech. Direct quotations have been left largely unedited to retain original wording and seek to capture the rhythm of conversation rather than conform to the norms of academic English writing.

\section{Findings: Marriage, Nationality, and Education}

The negotiation of multicultural identity occurs dynamically between structure and agency. Angelika Bammer states, "...home is about separation and commitment; and identity is at times about what we are essentially not, but are also not free to dispense with. The politics of identity, in short, is a constant process of negotiation" (1994, xiv-xv). Because of this, cultural and multicultural identity cannot be essentialized. However, the politicization of ethnic identity tends to be reductionistic. In the context of nation-states, the construction of "imaginaries of national identity intended to supersede all other identities...[creates] and [solidifies] socially constructed distinctions between insiders and outsiders" through "conferring or denying legal, social, and cultural citizenship" (Cainkar 2013, 128). The imbedding of power in citizenship opens and closes specific opportunities to individuals with differing national and legal standings. The dynamic between structure and agency is primary in the negotiation of multicultural, transnational migrant identity. As Catherine Bryan says, "Responding to these opportunities and restrictions and reflecting the complexity of migrant decision-making, these strategies are at once reactive and creative, responsive and adaptive, and complicit and subversive" (2012, 133). In the following sections on marriage, nationality, and education, this dynamic between structure and agency will be further explored. Rather than examining factors in isolation, I include multiple characteristics of participants, namely gender, ethnic minority 
identity, and national identity, in an effort to "simultaneously analyze other particular identities of an individual which [contextualize] identity relations, agency, and manifestations of power" (Rodriguez 2000, 162).

\section{Marriage: Cultural Commonality}

Asma leans forward as she speaks. "The main thing if I talk about the early marriage or the education part is the same. It's the same in the Baloch of Oman, same in the Baloch of Kyrgyzstan, Iran, it's the same." Asma gestures, emphasizing the importance of her statement. "It's the same. Because we all originally are Baloch. So, we have the same things in common." A recent graduate from university with a Bachelor's degree in engineering, Asma is working as a translator at a well-established hospital in Al Ain.

She sits next to me on the cushioned booth of the mall coffee shop and continues, "So that's why my mom says, she says if a guy comes from Oman and he's Balochi, we wouldn't mind to make him our son-in-law if he's good. So, what I mean is, he should be a Balochi no matter from which part." At 24 years old, Asma is single, ${ }^{1}$ unlike most of her cousins who married around the age of 18. In Balochi culture, marriage is spoken about as an expectation rather than an option. Asma is expected to marry first since she is the oldest of five children. Her two sisters do not have the pressure to marry because they are in grade school, under 18 years old, and their sister Asma and two older brothers are likely to wed before them. Having completed her undergraduate degree in engineering, Asma knows her mother is ready for her to be married. In considering a marriage partner, her parents deem Balochi heritage an essential characteristic. Asma explains, "'cause we all have the same culture, the same food habit, the same dressing style, everything is same." Balochi culture is framed as a basis of sameness on which communal, ethnic and familial identity is built. Although the diaspora of Baloch people is spread across many countries, the culture and ethnic identity remains an essential foundation of commonality for marriage. Citizenship is not considered an important factor, especially compared to ethnic identity expressed in communal association and cultural expression. These priorities expressed by Asma correspond with the lives of the other women I have spoken with who are married or engaged to exclusively Baloch men holding various nations' passports. Gesturing toward me, Asma continues, "I think you would feel more comfortable with someone who's from your own." She pauses as I nod my understanding of partiality toward ingroup socializing (Horwitz and Rabbie 1992, 265).

Asma goes on to contrast her parents' preference for a marriage partner from the same cultural background with her peers' "development in their thought" and "openmindedness" for difference. The conversation around love marriages could be attributed to a Western, modernist framework of "development" and a postmodern valuing of "open-mindedness" and plurality (Hinojosa 2009; McHale 1992). Studying and working in the UAE is a cross-cultural experience where Baloch women have opportunity to interact closely with different cultural values and expectations. However, Asma has not seen the "modern" pattern of meeting someone, getting to know them and then marrying among her Balochi community, "us." Across the table, her two younger sisters stir their hot chocolate, half listening to our conversation.

"So sometimes...for my mom I used to tell her, what if I find someone at work and I would say like I want to marry so and so. She used to be like, 'NO."' She pauses for emphasis. "'Should be from our place. Should be a Balochi.' I used to tell her, 'We're getting developed and people are open-minded. Time has changed.' But no, she still wants to follow her own, old plan. So, let's see. I might change the history." Her sisters smile at the reference to this familiar conversation. The preference for cultural homogeneity in marriage within a multicultural context creates tension between generational expectations. As an individual who has grown up in a multicultural context, Asma narrates this tension with language of "developing" toward "open-mindedness". Modernity is understood through the lens of orientalism, framing the "West" as bringing enlightenment and development to the "East" (Said 1978). However, she frames these changes in positive language, 
recognizing her personal agency to "change the history." This tension of multiculturalism ties back to the dynamic relationship between expectations and the personal choices that are made. Structures and history of power dynamics shape the grounds on which an individual makes decisions. Asma's parents insist that her husband must be of Balochi descent to be a candidate for marriage. Personal agency, in turn, reinforces or challenges structures; in Asma's words, she can "change the history." Asma's choices are made in conversation with these expectations. She does not completely reject or accept their expectations, but instead her language points to a more nuanced response. She holds her respect of her parents, their opinion, and cultural tradition in tension with her own willingness to defy expectations. This tension can be attributed in part to Asma's experiences in mixed-gender classrooms and work environments as well as the large expatriate population in the UAE.

Perched on the edge of the bed, I sip my tea, listening carefully as Noora describes her marriage. This is not her first marriage, she explains. Her countenance changes as she speaks, indicating her emotional response to painful memories. She was married to a cousin in Iran. In general, marriage to a cousin or relative is preferred over marriage to a family friend or a love marriage. Sitting in her mother's home nursing her youngest son, Noora recalls her experiences that seem so distant from her present circumstances. When she moved to Iran to join her husband, she experienced firsthand the differences in lifestyle and values between her extended family in Iran and her family in the UAE. Everything was unfamiliar in Iran from the food to "the way of life." She pauses as she collects the right words to communicate to me. Her first husband smoked hashish, a form of cannabis. After only four months of marriage, she came back to the UAE to rejoin her family.

I smile at the sight of her four-year-old son peeking shyly through the cloth that divides the bedroom from the sitting room where Umm Rashid and her husband sit talking and watching television. The TV across from me in the bedroom fades into white noise as Noora continues her narrative. Two years after her return to the UAE, she was engaged again. This time, her husband is a friend of her brother. During their six-month engagement, her fiancé came to visit with her. Her face is bright with expression as she highlights the difference of her second marriage. They love each other, she explains. Now, with three young sons, she lives in her mother-in-law's home. Watching her eight-year-old son run in and out of the room with his young cousins, she muses. Life is like her friends' lives. It has the normal busyness of chasing after her sons and the sounds of them fighting.

Noora's personal narrative illustrates the effect displacement has on marriage and crosscultural factors. While Asma emphasized the sameness of Balochi culture creating foundational similarities for marriage, Noora's experiences highlight the possible disconnect in the practical application of this ideal. Having grown up in the UAE her whole life, her marriage to her cousin had less cultural commonality than her current marriage to a Balochi family friend in Al Ain. This does not contradict Asma's theorization of cultural commonality as a basis for marriage. However, it suggests the primacy of cultural commonality over kin endogamy in the context of marriage for Balochi people in the UAE. The impact of this reprioritization is the weakening of familial ties arising from differing categorizations of licit and illicit behavior and the simultaneous strengthening of collective identity through shared experiences and practices.

The light of the late afternoon sun peeks through the doorway behind Somia and she stands to turn off the lights and close the door. Sitting in the darkness of the majlis, she projects a video from her mobile phone onto one of the heavily tapestried walls. Somia is a friend of my mother's friend in her late twenties and she readily invited me into her mother's home in $\mathrm{Al}$ Ain, preferring to meet under her mother's roof rather than her mother-in-law's. ${ }^{2}$

As images of women dancing flit across the walls, Somia and her eldest sister Mona begin to identify the clothing. "This one is Emirati...this one is Bahraini...this one is Hindi [Indian]...." 
The mosaic of colors, cloth, and faces flicker as the women in the video celebrate the imminent wedding of Somia's cousin. The women at the leilat al-henna [henna night] chose to put on clothing from a variety of cultures and nationalities with which they had varying degrees of personal association. The multipleday event of a wedding gives these women, and especially the bride, opportunity to wear numerous outfits. Their choices to wear different symbols of national and ethnic identity are not necessarily statements of their own personal background or legal identity. In a country comprised of minorities, the choice to put on a certain national or ethnic dress cannot be understood as assimilation by a singular minority to a standard set by a singular majority. Rather, as a member of a minority among minorities, Somia narrates cultural exchange across national differences in terms of personal agency. The choice to wear aspects of a specific culture in a certain setting is foundational in expressions of multiculturalism. Wedding guests, as well as the bride and her family, may choose to wear clothing that represents their ethnic heritage or national identity, or they could wear the dress of nationalities to which they have no personal connection. When asked why they chose to wear a certain style of dress to their wedding, Somia referred to personal preference as her primary motivation while Asma attributed it to "mixed culture." Asma described the logic of "mixed culture" saying,

Maybe I see some people from Western country, I see some from Eastern, and I see their cultures. Maybe I want to try them, or some of them I just adapt to those cultures. So, the more you live with them, you learn how their life is and you put it into your own life and that's how it becomes... I see weddings here, people over here, they all wear white, and the things are like that, you would want to do that, right? Even if you don't want to, you see everyone doing it. It has become like a trend.

Multiculturalism, or "mixed culture", results from close interaction and sought understanding between different cultures (Bhabha 1996, 59). Personal agency is primary in choosing to adopt customs and symbols of other cultures. Asma attributes some changes in cultural expression to social shifts and "trends" that may even bypass personal desire and preference. She admits that her view is in preference of "the old way." However, she sees the power dynamics at play in the conversation of modernization and multiculturalism. She voices her peers' perspectives, “They say, I'll go how the world is going. The other [reason things are changing] might be the development in their thought. Like maybe they want to grow up, they want to change their cultures, they want to be more modern." Living as displaced people in a country where every nationality and culture is a minority, cultural exchange is almost inevitable. In addition to the multicultural dynamics present in the UAE, there is a strong influence that is framed in orientalist terms of modernity (Said 1978).

While Asma spoke of sameness and cultural commonality in Balochi culture, wedding celebrations in both her and Somia's experience are a multicultural endeavor. Though practices and choices of individuals are shaped by their experiences and preferences, it would be an oversimplification to ignore the dynamic interaction between agency and structure. As Sherry Ortner wrote, "history makes people, but people make history" (Ortner 2003, 277). Somia and Asma synthesize culture moving between their abstract description of culture and their daily practical choices.

\section{Nationality: Citizenship and Nationalism}

Sitting next to a sprawling spread of assorted nuts, chocolates, tea, and sweets, Somia pours another cup of hot chai [tea] next to my half-full cup of coffee. "You know, many people when they said, 'What's your family name?' 'I am Balochi' 'Really?!' She exclaims, her face mimicking an expression of the surprise she has seen. "They are surprised because they think, 'They don't know, they don't have education."' Blending the voice of a hypothetical observer with her own, she explains, "I don't want to say bad, but most from Pakistan don't have education too much. Not because they don't have, but their life is different." Somia's words reflect the experiences of Ameera, one of 
the youngest daughters of Umm Rashid and Noora's younger sister. Ameera expressed that other people cannot recognize her family's Balochi ethnicity and heritage until they are told. Once told, they are often surprised to hear they are Baloch and not Emirati. She attributed this confusion to the clothing they wear in public, which is the Emirati abaya, a long black robe worn by women on top of their clothing, and kandura, a long white robe worn by men. Without visual distinctiveness, the Baloch people can choose to claim or disassociate from their Balochi identity through outward cues such as their clothing. These choices in symbolic practice are related to the generation and age of participants as many of the older generation with closer ties to Balochistan still choose to wear the distinctly Balochi dress, at times layering the abaya over their Balochi outfit, paralleling their layering of identities that are worn or discarded. The perception of Baloch people is tied to reductionistic generalizations regarding socioeconomic status and educational attainment. These simplifications shape both the outsider's expectations of Baloch people as well as the Baloch women's personal symbolic representation of otherness or assimilation. A double consciousness, defined by Du Bois as the "sense of always looking at one's self through the eyes of others," is expressed by these Baloch women in their negotiation between personal preference and external response (1903, n.p.).

Longevity of residence in the UAE promotes assimilation to local culture. Somia explains, "They see me, I am different than somebody come just a few years. It is different when you born here. Your life all in UAE. Of course, you do all things same as this country!" Somia ties her culture and lifestyle to the norms of the Emirati people. Without alluding to or exclusively affirming her Emirati citizenship, she highlights the cultural similarities of Baloch people living their whole lives in the UAE to the local culture, attributing the similarities to extensive exposure and successive assimilation to the Emirati culture.

Continuing her negotiation with theoretical opponents to her perspective, she represents and argues against their perspective, stating

They don't think that the world will be different, be changed. You stay long time in UAE, you should have this nationality. They think no. One day, maybe I go back to my country. But it is very hard. My life is here. I don't know anything about my grandfather and mother country. Why I go back? Because you know? ...We are Sunni. And they have [in Iran] Shia, too much. And that is very hard.

Somia ties in religious practice as a point of tension in her transnational identity construction. Though her family is historically from Iran, the pressure as a religious minority pushes her toward closer association with Emirati culture. Familiarity, tied to personal experience and religious identity, plays an important role in her nationalistic feeling toward the UAE and the lack of ties to the country of her ancestors.

Somia's narrative mirrors Noora's words, telling me that when her sons visit Pakistan, everything is unfamiliar. They continuously ask, "What is this?" as they experience an environment and culture they are unaccustomed to, even though their passports may say they are home. Somia and Noora's families have a sense of nationalist identity rooted in their recent family history and cultural assimilation to the $U A E$, regardless of historic and official non-Emirati identities.

"And we don't want to lose our UAE [citizenship], go to Iran. Why? My country is UAE. Khalaas [finished]," Somia states, indicating her hypothetical debate is definitively over. "My life, my all things are in this country. And my nationality." Somia claims the UAE as her own because of her cultural and religious continuity with the imagined community of the Emirates. Benedict Anderson theorized nationalism as the creation of an imagined community, arguing that "nationalism has to be understood by aligning it, not with selfconsciously held political ideologies, but with the large cultural systems that preceded it, out of which - as well as against which - it came into being" (1991, 12). Somia's legal status as a citizen is secondary to her personal association with the cultural practices, or as she says, "all things" in the UAE. 
In response to my question if their UAE citizenship provides benefits, Somia exclaims, "Yes, too much. You know, education and medicine. Many, many things are free. Free!" Turning from her older sister, Mona, lounging on a couch across the room from us, Somia translates her words for me. "You know, she said 'No country like UAE. No country."' While her passport resonates with her nationalist feeling toward the UAE, the benefits of citizenship are an additional advantage. Her response calls to mind Noora's desire for her children to have local passports in addition to their expatriate Pakistani citizenship. As Somia indicated, the local passport provides many resources including free education. Noora experienced the impact of the lack of Emirati citizenship, and thus lack of access to public school, as well as being unable to afford a private education. Instead, she studied her older sisters' textbooks at home for seven years, later teaching her younger siblings. Noncitizens expressing such strong feelings for their country of residence highlights the limitation of defining nationalism in terms of formal citizenship (Ong 1999). Families such as Noora's, living in a state of suspension between their personal, national and cultural association with the UAE and their legal status as nonEmiratis, must work to create a sense of stability in their liminal state (Turner 1969). This includes the creation of alternatives to the educational options unavailable to them.

Many displaced Baloch people find themselves in a state of liminality marked by two spheres of identity and place: the Emirates and Balochistan. Where Somia and Noora feel a sense of nationalism toward the UAE, Asma expresses a closer tie to Pakistan, describing traditional cultural practices and symbols as present "back in country." Many members of her extended family are displaced in other emirates and countries in the region while others are still in Pakistan. Within Pakistan, most of her family has lived in the city of Karachi in the southeastern Sindh province for generations. The conflicts occurring in Pakistan affect her relatives and she hears about bombings and attacks from their firsthand accounts. Her identification with Pakistan could be attributed to her family's more recent history in the UAE, with her father as the first generation to move to the UAE in 1996 when Asma was young. Having moved numerous times to different villas within Al Ain, the sense of instability of place compounds her family's displacement in the UAE. Nancy Hornberger identifies the in-between as transnationalism, defined when an individual "moved bodily across national borders while maintaining and cultivating practices tied - in varying degrees to their home countries" (2007, 326-7). In turn, transnationalism "lends itself to a dually-linked process of 'becoming other' to both home and host national-cultural contexts." Asma's sense of security is not tied to cultural context as much as it is grounded in her relationship to her immediate family. When she gets married, she wants to stay close to her family, wherever they may be, simply stating, "Home is home. Family is family."

In contrast, Umm Rashid relates to her Pakistani citizenship in different ways. Though given the chance to vote in a recent election in Pakistan, Umm Rashid admits she has no interest. The twenty years she lived in Pakistan are superseded by the forty years she has spent more recently in the UAE. She has a deep respect for the Sheikh and his development of the Emirates, contrasting his investment in the people of the UAE with the government in Pakistan that "eats the money" instead of giving it to the people. For Umm Rashid, her sense of nationalism is related to her respect for the government and forms of structural power. Her disengagement with civic functions such as voting indicates a distancing from her passport country.

Her daughter Noora mirrors her perspective saying her impression of Pakistan is that there is always fighting on the TV. She states simply, "Those are not my people. That is not my government." Noora disassociates from not only the civic implications of her official nationality, but her national identity itself. Regardless of her legal status, she aligns her identity with the UAE rather than Pakistan. The tension between two spheres of Emirati and Balochi identities highlights the negotiation of intercultural identities crossing lines of personal and legal association. 


\section{Education: Gender, Opportunity, and}

\section{Desire}

"When a person is uneducated, his thoughts, he will not look to the future... He just looks at the present, what is there, what is not there." Yasmin is a young Baloch woman a few years and entry level jobs past her high school graduation. Sitting across a small coffee shop table, she draws a sharp contrast between life with and without an education.

"[An uneducated person] doesn't look to the side effects of a thing. Just he is not caring that much. When a person is educated, he will know, he will think before doing that thing." Yasmin conceptualizes education as a strategy of character building. The high view of agency implicit in her narrative is also marked by the dynamics of gender that are present in numerous aspects of her life, including her gendered word choice. Speaking in similar terms about education, Asma reflects, "I would say, a girl educated can have a better married life compared to an uneducated one." Education is both a means of becoming and it shapes the trajectory of desire (Deleuze and Guattari 1972). For both Yasmin and Asma, education is an accomplishment of personal growth that can be then used to describe an individual.

The conceptualization of education as a means of becoming provides a basis for personal goals. However, the implementation of desire is dependent on opportunity. When asked about her dream job, Yasmin laughs, "I want to be an investigator...You see now it was just a dream. But still, I like that thing, a thing which I like. I can't, we don't get." Yasmin quickly qualifies her dream of being a detective, highlighting the understood distance between her desires and real opportunity. As a daughter, she experienced inconsistent support and intermittent discouragement of education, making the pursuit of her high school diploma difficult. This uncertainty of familial support translates into her future hopes and endeavors. Similarly, in response to the inquiry if her husband allowed her education, Somia diplomatically said, "He allowed and not allowed. Sometimes he, yanni [I mean], he see many things in my life differently...the dinner not at times because you come late. Ok, but the life is going." Somia is studying at level 7 at UAE University, an internationally accredited institution founded by Sheikh Zayed bin Sultan Al Nahyan. After completing her general education requirements at level 9, she will choose her major and hopes to graduate two years later, "inshallah [if God wills]." The dual "allowing" and "not allowing" dynamic with her husband highlights the inconsistency of opportunity, even as she is in the middle of her studies. This is reinforced by her history of leaving university and the pursuit of education when she first got married. Education and marriage, while not contradictory, are held in tension as the role of women is disputed. Agency to follow desire, for Baloch women, is uncertain and limited as male authority holds the power of opportunity.

Although the opportunities to follow desires are contingent on patriarchal support for many Baloch women, the dynamic between structure and agency is not necessarily antithetical. The conversation about Yasmin's dream job is quickly followed by a conversation around marriage. When asked if she will marry, Yasmin immediately responds, "Yeah, I'm engaged now." After exclamations of congratulations Yasmin expounds. "I was thinking, no, it's not that compulsory, but he proposed so I accepted. It was actually love marriage." Yasmin smiles and explains that her parents are still unaware that she met and knows her Baloch fiancé personally as a high school classmate. Instead, her marriage was orchestrated officially as an arranged marriage through her connection to her fiancé's sister and her brother's work with his father. This narrative of formalizing a self-arranged love marriage is one that is familiar, though the details of maneuvering may vary. ${ }^{3}$ Rather than seeing arranged and love marriages as mutually exclusive, Yasmin creates the marriage opportunity that she and her fiancé desired. Unlike her educational opportunity, she is able to increase her agency in marriage decisions by utilizing patriarch-centered systems of acceptability in conjunction with her desired choice. She narrates her negotiation of her multicultural identity with the contrasting expectation of arranged and love marriages, seeking to balance cultural and familial expectations with individual agency and desire. 
Desire for education and personal development is not necessary for opportunities to arise. In some cases, opportunity may inspire interest. Asma highlights this concept with her narrative, explaining, "I feel there's a change [in culture] because my dad made me, made me fulfill everything...He was always an encouragement for me, even regarding my license, I never wanted to drive." Although Asma highlights the male support of women's education, the masculine gaze is intrinsic in the patriarchal encouragement of female education and the dependency of educational opportunities on a male figure. Before learning to drive, Asma did not have the desire to pursue her driver's license. Now, Asma admits, "I used to be scared, but no more. Yeah, I'm a safe driver, but at the same time I enjoy it...Now I'm a person who drives like I'm driving in a race track." The patriarchal encouragement of Asma's education provided her the opportunity to earn her driver's license and, despite the original lack of interest, Asma came to desire the skills and experience she attained through learning to drive. Opportunity does not always need to follow desire, but they may arise simultaneously.

At the risk of representing Baloch women as helpless and lacking agency, it is important to recognize that they have heterogeneous desires (Abu-Lughod 2002). When asked about the most important things in her life, Yasmin first responds, "Complete my education." Her definition of completion is a minimum of attaining a Masters degree in Business and Commerce. Yasmin's ambition directly contrasts the perceived lack of value in educating women that Asma explains, saying, "They believe that girls don't have to study so much 'cause they end up in the kitchen." The logic of not educating women because of their traditional role is in the kitchen is based in an underlying assumption of marriage and motherhood as essential in femininity. This logic dichotomizes the roles women can have, placing a professional identity in opposition to maternal and familial roles (Shields 2008). Women, including engaged Yasmin and married Somia, live out the intersectionality of their social roles as both student and fiancée/wife. For Yasmin, Asma, and many other Baloch women, education ranks high in desire and value.
In contrast to these women's desire to continue studying, Ameera, Umm Rashid's youngest daughter, readily told me that she did not want further education. She was privileged to graduate from high school, but she did not enjoy it and is glad to be done. She explained that she did not want to go to university because she is now married with a young almost four-year-old son. While her older sister Noora borrowed books to supplement her education after she was taken out of school, Ameera has the possibility to study at university, but lacks the desire. Haleh Afshar notes that it is important to "discard the undertones of weakness and subservience that have generally been attributed to terms such as motherhood, marriage and domesticity and respect the choices made by non-Western women" $(2005,1)$. Rather than framing her decisions in terms of oppression, Ameera's disinterest in further education could be attributed to a different conceptualization of education. She does not see education as a means of self-improvement, but regards it as an option to be an alternative self from the one she desires. The rejection of education for Ameera signals her placement of a higher value on her identity as a wife and mother than the potential identity she could possess as a university graduate.

Shifts in gender roles and perceptions shape structural level changes in opportunity. Asma describes new understandings of men and women, stating, "We're all considered equals. So this shows how different today's culture is from our past culture. So I would say that's really amazing. As long as we are going faster, the generations are changing. Their thoughts are also changing." Rather than reducing culture to static understanding and application of tradition, Asma describes the logic of culture as dynamic, interacting with the multiculturalism at play in the UAE that challenges the basic principles of every culture (Turner 1993).

In addition to the cultural changes described, lack of agency and opportunity when there is a strong desire for education can result in resolve for the next generation. In Asma's case, her father was taken out of school as a child after a few years of study to work in a garage to help 
support his family financially. Similarly, Asma's mother completed seventh grade and her brother began telling her, "You're grown up now. You don't go out. You don't study." Their collective experiences led to their commitment to support their children through higher education. Asma was able to receive her private university education in Al Ain University of Science and Technology because her mother became a businesswoman to supplement her father's work, buying supplies and selling her intricately crocheted clothing. Because of her parents' sacrifice to support her education, Asma says, "So today wherever I am, I will thank them because they didn't see how hard our time was, but they made me what I am today." The lack of opportunity and agency to follow desire fostered the proactive support Asma's parents give their children, shaping their children's actions and use of agency.

Differing views on women's role and appropriate educational aspirations can cause tension within Baloch communities with shared history. In diaspora communities, this can create distinctions between those displaced and those "left behind." Asma draws sharp distinctions between her experiences and the lives of her cousins in Pakistan. Her uncles often questioned her parents' decision to support her private university education, pointing out Asma's singleness as a correlated factor to her educational identity. Asma mirrors the inverse correlation of education and marriage saying,

Now they [my cousins] all are married. With kids... after finishing their school, high school, grade 12 or grade 10, they just got married. Some of them didn't even study. I wouldn't blame them, some of them. Their parents didn't let them, like my father's, a few of my father's brothers, they believe that girls don't have to study so much 'cause they end up in the kitchen. That's what they believe. So they didn't study. And some of my cousins didn't want to study, so it's either both the ways.

The two reasons that Asma's female cousins did not pursue higher education are the lack of opportunity from their fathers and the lack of desire. In this way, both patriarchal power and personal agency are portrayed as potentially resulting in a similar adherence to a maternal and domestic role. However, it is worth noting that Asma's description presents her cousins as usually completing high school, a level of education that is dramatically different from the limited years of schooling her parents received in a similar geographical context. This suggests that there has been a change in educational expectation from a familial, cultural or legal perspective. The decisions to marry and to study beyond high school are understood as conflicting pursuits. To truly pursue one, the other must be indefinitely postponed. Asma describes her decision saying, "Even in my case, when I finished my high school, my dad asked me if I would want to marry. He asked me, and I said I would want to study. So I continued and today I believe I have done the right choice." The choices Asma and her family made through her completion of a Bachelor's degree reflect a prioritization for personal development, conceptually tied to education, over the social and cultural expectation of marriage and motherhood. Her desire and choice to pursue a university degree aligned with the financial and personal support of her parents that provided a viable opportunity to study. Asma summarizes her pursuit of education with the simple words, "It was my dream and I completed it."

\section{Conclusion: Multiculturalism as Embrace and Critique}

As Baloch women construct their intersecting Balochi and Emirati identities, cultural commonality plays an important role in perception from others and self, marriage relationships, and nationalistic feelings. While abstract Balochi culture is narrated on the basis of sameness, symbolized in clothing and marriage practices, assimilation to local Emirati dress commonly creates ambiguity in perceived identity. Multiculturalism emerges in clothing choices as international fashion trends and, more broadly, international markets inform preference. The spirit of nationalism toward the UAE and the Emirati government results from personal history and personal association with place. Such nationalist sentiment can arise regardless of actual citizenship as Baloch women may have mentally left behind the 
nation of their ancestors even though they do not have legal status in their adopted country. Official citizenship, in addition to the relationship between women and patriarchs, affects educational opportunities. Women's responses to these opportunities vary as they conceptualize education as a trajectory of selfimprovement and a means of attaining an alternative identity. Desire and real opportunities meet inconsistently in the intersection of these individuals' identities as daughters, mothers, wives, ethnic minorities, and women.

Further research on the perception of Baloch people by the local Emirati people would nuance understanding of the Balochi presence in the UAE, providing complimentary perspectives to self-representation. One limitation of this project was the short span of research. A longitudinal project regarding the Baloch people would allow for greater collection of data and a richer exploration of themes introduced by this paper. Narratives of Baloch men would provide contrasting perspectives on marriage and national identity, especially as they relate to topics of nationalism, gender and education differently in a patriarchal society.

Multiculturalism can be theorized as a process of constructing a cohesive cultural identity outside, in between, or within the bounds of nationality. To construct multiculturalism outside of national identity is to reject the conversation of nation-states and citizenships as unnecessary in multicultural identity. For example, individuals who do not identify culturally with their passport country may seek to distance themselves from nationalistic discourse by rejecting the value of national identity. However, such a stance prevents groups from challenging and redefining the nation-state as an imagined community. To construct an identity in between has the potential to bring together unique and distinct cultures and create something new. The weakness of this theorization is that it removes multicultural identity construction from direct negotiation with majority and minority identities and cultures. The Baloch women who participated in this project constructed their multicultural identity within the conversation of national identity. Their identity did not fit into the simplistic definitions and assumptions that national identity would be synonymous with citizenship. However, by negotiating their sense of self within they could simultaneously acknowledge and reformulate the construct of national identity. Thus, constructing a multicultural identity within requires a place within contemporary conversations of nationalism.

The tension of holding multiple cultures in a unified individual identity has implications for numerous topics including refugee movements, as transnational people seek to create a sense of stability in a geographically and politically turbulent lifestyle. National identity, distinct from passport identity, follows from cultural commonality and has the potential for stronger loyalty than legal citizenship. Many refugees and transnational individuals become "other" to both their original and their host context and may create a sense of home in relationship to immediate family and community. A distinct legal national identity has less priority over community with people of shared culture and experience as well as understanding and exchange across cultural differences. Conversations on women's rights, especially as they relate to education and marriage, must carefully consider the dynamic relationship between opportunity and desire rather than giving simplistic responses to complex power dynamics. Racial and ethnic minorities will benefit from constructing their multicultural identity within contemporary conversations as this provides an opportunity to "challenge, revise and revitalize" the values and assumptions of both majority and minority cultures (Turner 1993, 413). Multicultural identities are expressed in diverse and distinct ways as individuals actively respond to and reshape structures and cultural expectations. For the women who participated in this project, multiculturalism is not a complete rejection of one culture to embrace the other, but the simultaneous embrace and critique of both without contradiction. 


\section{Acknowledgements}

I am truly grateful to the women who participated in this project for sharing their lives, and to my advisors, Dr. Christa Tooley and Dr. Christine Folch, for their guidance. This work was made possible through the financial support of the Global Scholar Award from Wheaton College's Center for Global and Experiential Learning. Thanks K\&T for graciously hosting me, T\&M for sharing contacts and contextual knowledge, Esther Han for countless hours of transcription, and Abigail Bowman, Bethany Thomas, Lauren Palmer, and Sarai Lopez for additional help. Most of all, thank you to my family for unending support, encouragement, and investment.

\section{Endnotes}

${ }^{1} \mathrm{~A}$ year after these interviews, Asma married a Baloch man in an arranged marriage.

${ }^{2}$ The invitation into a space is shaped by the dynamics of authority that are present at her mother-in-law's house. Noora explained her similar preference to host me in the small bedroom she lived in with her husband and two young sons rather than the main majlis of the house, saying, "If I go out [of the bedroom], it is the house of my husband's mother and my husband. Here in this room is my space. I am ruler of it." Power dynamics inhabit space. The mother of the house has a level of authority and scrutiny that can be placed on the younger women of the house. This shapes the lack of ownership of space Somia and Noora feel in their mother-in-law's homes and their claims to owning space through hospitality. Marriage creates new dynamics of inhabited space and tangibly restructures the power dynamics these women literally inhabit.

${ }^{3}$ Asma later described her new marriage as "arranged and then love", mirroring Yasmin's engagement that she narrates through both love and arranged marriage. 


\section{References}

Abdullah, Muhammad Morsy. 1978. The United Arab Emirates: A Modern History. New York: Harper \& Row Publishers, Inc.

Abrahamian, Atossa Araxia. 2015. The Cosmopolites: The Coming of the Global Citizen. New York: Columbia Global Reports.

Abu-Lughod, Lila. 2002. “Do Muslim Women Really Need Saving? Anthropological Reflections on Cultural Relativism and Its Others." American Anthropologists 104 (3): 783-790.

Afshar, Haleh. 2005. Women and Politics in the Third World. New York: Routledge.

Ali, Syed. 2011. "Going and Coming and Going Again: SecondGeneration Migrants in Dubai." Mobilities 6 (4): 553-568.

Anderson, Benedict. 1983. Imagined Communities: Reflections on the Origin and Spread of Nationalism. London: Verso.

Bammer, A. (1994). "Introduction." In Displacements : Cultural Identities in Question, edited by A. Bammer. Bloomington: Indiana University Press, xi-xx.

Bhabha, Homi K. 1996. "Culture's In-Between," In Questions of Cultural Identity, edited by Stuart Hall and Paul Du Gay, 53-60. London: Sage Publications, 53-60.

Bryan, Catherine. 2012. "Gendered Returns, Ambivalent Transnationals: Situating Transnationalism in Local Asymmetry." Anthropologica 54(1): 133-142.

Bureau of Democracy, Human Rights, and Labor. 2008. “United Arab Emirates" from 2008 Country Reports on Human Rights Practices. Accessed May 13, 2017, https://www.state.gov/j/drl/rls/ hrrpt/2008/nea/119129.htm.

Cainkar, Louise. 2013. "Global Arab World Migrations and Diasporas." The Arab Studies Journa/21(1): 126-165. http://www.jstor.org/ stable/41968271.

Central Intelligence Agency. n.d. "The World Factbook - Central Intelligence Agency." Accessed January 30, 2017.

https://www.cia.gov/library/publications/the-world-factbook/ geos/ae.html. 
Davidson, Christopher M. 2006 "After Shaikh Zayed: The Politics of Succession in Abu Dhabi and the UAE." Middle East Policy 13(1): 42-59.

Deleuze, Gilles and Félix Guattari. 1972. Anti-Oedipus: Capitalism and Schizophrenia. London and New York: Continuum.

Du Bois, W. E. B. 1903. The Souls of Black Folk. New York: Bartleby.com, 1999, accessed January 30, 2017, http:// www.bartleby.com/114/.

Eller, Jack David. 1997. “Anti-Anti-Multiculturalism." American Anthropologist 99(2): 249-256.

Hornberger, Nancy. 2007. "Biliteracy, Transnationalism, Multimodality, and Identity: Trajectories Across Time and Space." Linguistics and Education, 18(3-4): 325-334.

Horwitz, Murray and Jacob M. Rabbie. 1982. "Individuality and Membership in the Intergroup System." In Social Identity and Intergroup Relations, edited by Henri Tajfel, 241-274. Cambridge: Cambridge University Press.

Ong, Aihwa. 1999. Flexible Citizenship: The Cultural Logics of Transnationality. Durham \& London: Duke University Press.

Ortner, Sherry. 2003. New Jersey Dreaming: Capital, Culture, and the Class of '58. Durham: Duke University Press.

Rodriguez, Alicia P. 2000. "Adjusting the Multicultural Lens." Race, Gender \& Class 7(3): 150-177.

Said, Edward. 1978. Orientalism. New York City: Pantheon House.

Shields, Stephanie A. 2008. “Gender: An Intersectionality Perspective." Sex Roles 59: 301-311.

Turner, Terence. 1993. "Anthropology and Multiculturalism: What is Anthropology That Multiculturalists Should Be Mindful of It?" Cultural Anthropology 8 (4): 411-429.

Turner, Victor. 1969. The Ritual Process: Structure and Anti-Structure. Chicago: Aldine Publishing.

Zacharias, Anna. 2013. "Bidoon celebrate UAE National Day as Emiratis." The National, Nov 24. Accessed December 22, 2015. http://www.thenational.ae/uae/heritage/bidoon-celebrate-uaenational-day-as-emiratis.

Zayed University. "The Story of the UAE." Accessed January 30, 2017. http://www.zu.ac.ae/main/en/_careers/living/story.aspx.

(c) $(1)(9)$

This work is licensed under a Creative Commons

Attribution-NonCommercialNoDerivatives

4.0 International License. 